\title{
Cuts force UK astronomers to drop key role in gamma-ray satellite
}

London. British astronomers have been told that they will not be provided with funds they need to play a leading part in the construction and exploitation of a new ECU322-million(US\$396-million) gammaray satellite, Integral, initially proposed by Britain, which is planned for launch by the European Space Agency (ESA).

The lack of funds is a direct result of decisions by the Office of Science and Technology to put pressure on ESA to reduce its space science budget, and not to provide the Particle Physics and Astronomy Research Council (PPARC) with funding for any new domestic scientific projects in the financial year 1995-96.

Anticipating such a squeeze on its funding, PPARC had already asked ESA to delay any decision about allocating contracts for the payload for Integral, adopted in 1993 as ESA's next 'medium-scale' mission, until after a meeting of the space ministers of the agency's member states, planned for next November.

Britain is hoping to use this meeting to persuade other ESA members to accept a reduction in the agency's science budget. It argues that tactics that have already proved successful in reducing the overhead costs of the European Laboratory for Particle Physics (CERN) can also be applied to the space agency (see Nature 372, 712; 1994).

But Britain's request has been angrily rejected by Roger Bonnet, director of ESA's scientific programme. He says that, even if Britain is unable to contribute to the payload costs of Integral (the satellite itself will come out of ESA's central funds), the mission will still proceed, but on a reduced basis. Italy has already offered to take over some of Britain's planned role.

Two main instruments planned for Integral will be affected. The first is one of its two large gamma-ray telescopes, an cae- sium iodide imager, for which a British research team headed by Tony Dean at the University of Southampton had already been identified as the most likely principal investigator, as much of the development work has been carried out in the United Kingdom.

O rigin a $11 \mathrm{y}$ planned as a joint UK/Italian project, it now appears that the Italians may now be prepared to cover all the costs of the imager and that, as a result, Italian scientists will have privi-

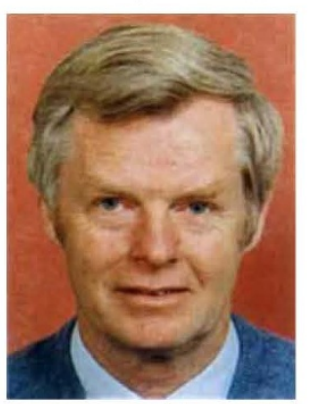

Pounds: problems are 'price of success'. leged access to data sent back over the first year, as is customary practice.

The second instrument is an optical transient camera, which had been planned as a joint project between Britain and Ireland. According to PPARC officials, it now looks as if this will be scrapped altogether.

David Hunt, the science minister, announced last week that PPARC has been awarded an overall budget increase of 4.8 per cent next year (see page 464). But most of this will go towards paying the extra costs of the UK subscription to CERN caused by the fall in the value of the British pound compared to the Swiss franc (in which currency the CERN subscription is paid).

There will also be an increase in the subscription to ESA, in line with previous commitments to the agency. But there will be no extra money left for increased spending on domestic programmes or new scientific starts.

Ken Pounds, PPARC's chief executive (and also professor of radioastronomy at the University of Leicester), says that part of the

\section{Advisers ignored over observatory head}

Munich. Italian astronomers are hoping to establish a better relationship with their new research minister, Giorgio Salvini, than they experienced with his predecessor Stefano Podestá. Last month, Podestá rejected without any explanation the nominee of the country's 15-strong council for astronomical research for the directorship of one of the most scientifically important of Italy's 13 observatories, the Brera Astronomical Observatory near Milan.

Instead, he renewed the term of the current director, Guido Chincarini, for a further three years. The move has angered astronomers, as it is the first time that the advice of the council - an elected body of scientists responsible for advising the research minister on matters relating to astronomy - has been ignored.

Giancarlo Setti, the vice-president of the committee, says that the committee is not complaining about the scientific merits of the two candidates, both of whom, he says, are "excellent scientists". But he says that the committee is concerned about the way in which the former research minister - who was often criticized for failing to listen to the scientific community during his sevenmonth term of office - appears to have rejected the committee's advice.

A. A. problem has ironically been the success of British scientists in winning a substantial role in a number of existing ESA programmes, such as Soho/Cluster solar mission, each of which has required substantial funding.

"One could say that we are suffering from indigestion, having just eaten a large meal," says Pounds. "But the result is that we are going to miss the next meal, with pressure on the council's domestic budget likely to lead to British groups not being able to play a significant part in Integral."

British astronomers, angry that the scientific fruits of many years' work designing experiments for Integral are likely to be plucked from under their nose by others, see it differently.

They argue that are being denied funding because Integral has become a pawn in the government's efforts to reduce the size of its ESA subscription.

"Integral has become part of a negotiating ploy," complains Gerry Skinner of the University of Birmingham's school of physics and space research. "PPARC's decision not to provide any money next year means that Britain will lose out both by not being able to carry out the hardware development programme for the payload, and through being denied access to that fraction of the data which will be 'top-sliced' by those who provide the payload."

Pounds and Bonnet were due to meet earlier this week to discuss the impact of Britain's decision on ESA's plans. Despite Britain's request for a delay in decisions over the contractors for Integral's payload, due in June, Bonnet is said to be keen to keep the mission on schedule in order to turn the agency's attention to its future programme, Horizon 2000+.

Even if Bonnet insists on proceeding with Integral without Britain, the agency's difficulties may be far from over. No one doubts the genuine desire (and ability) of Italian scientists to pick up the pieces. There is also an economic logic, given that the Italian aerospace company Alenia has already been selected as prime contractor for Integral.

A spokesman for the Italian Space Agency (ASI) said this week that various government agencies are discussing what level of contribution they may be able to make. But with the agency currently in turmoil, and facing a major task in renegotiating its previous commitments to the European agency, ESA officials are said to be cautious about how far Italian promises to fill the gaps left by Britain are likely to materialize.

David Dickson 